\title{
AGENESIS OF BILATERAL PERMANENT MANDIBULAR CANINE: A RARE CASE REPORT
}

\author{
Deepti Garg Jindal, ${ }^{1}$ Varun Jindal, ${ }^{2}$ Himanshu Singh, ${ }^{3}$ Swati Gautam, ${ }^{4}$ Ishita Bhojia, ${ }^{5}$ Arjun Chaudhary ${ }^{6}$ \\ ${ }^{1}$ Reader, Department of Oral Pathology and Microbiology, Bhojia Dental College and Hospital, Himachal Pradesh, India \\ ${ }^{2}$ Reader, Department of Conservative Dentistry \& Endodontics, Bhojia Dental College \& Hospital, Himachal Pradesh, India \\ ${ }^{3}$ PG Student, Department of Oral Pathology and Microbiology, M. M. Dental College \& Hospital, Haryana, India \\ ${ }^{4}$ PG Student, Department of Oral Pathology and Microbiology, Bhojia Dental College \& Hospital, Himachal Pradesh, India \\ ${ }^{5}$ Intern, Department of Oral Pathology and Microbiology, Bhojia Dental College \& Hospital, Himachal Pradesh, India \\ ${ }^{6}$ BDS Student, Bhojia Dental College \& Hospital, Himachal Pradesh, India
}

\begin{abstract}
Corresponding Author: Deepti Garg Jinda

E-mail:

drdeeptigarg08@gmail.com

Received: $3^{\text {rd }}$ January 2016

Accepted: $10^{\text {th }}$ April 2016

Online: $2^{\text {nd }}$ May 2016 canines bilaterally.

\section{INTRODUCTION}

Hypodontia is the congenital absence of less than six teeth whereas oligodontia refers to congenital lack of more than six teeth excluding third molars. Partial anodontia (hypodontia or oligodontia) involves one or more teeth and is a rather common condition. ${ }^{1}$ The most frequently occurring congenitally missing permanent teeth, excluding third molars, are the mandibular second premolar $(3.4 \%)$ and the maxillary lateral incisor $(2.2 \%){ }^{2}$ The absence of teeth may be unilateral or bilateral. There are reports showing unilateral occurrence of permanent mandibular canines but agenesis of bilateral (both right and left) mandibular canines is not well documented and literature shows paucity of data pertaining to this anomaly. The incidence of congenitally missing permanent canine was found to be $0.1 \%$ in the maxilla and $0.02 \%$ of mandible in a survey of congenitally missing teeth,
\end{abstract}

\begin{abstract}
Hypodontia is the congenital absence of less than six teeth because of agenesis. Congenital absence of tooth (hypodontia) from the dental arch, may occur with any tooth, most commonly being third molars, however, absence of permanent mandibular canine is rare. The absence of teeth may be unilateral or bilateral. There are reports showing unilateral occurrence of permanent mandibular canines but agenesis of bilateral mandibular canines is not well documented in the literature and comprehensive review of literature shows paucity of data pertaining to this anomaly. Here we report one such rare case of congenitally missing mandibular permanent
\end{abstract}

Keywords: Hypodontia; Tooth Agenesis; Oligodontia; Permanent; Mandibular; Canines.

excluding third molar in 6000 orthodontic patients by Rose. ${ }^{3}$

In this article we report a rare case of congenitally missing permanent mandibular canines bilaterally in a 43 year old male patient.

\section{Case report}

A 43 year old male reported to the out patent department complaining of stains in his teeth and wanted to get them cleaned. His medical history was unremarkable with no family history of congenitally missing teeth. Intraoral examination showed that the patient had missing left upper central incisor which was extracted because of trauma and mandibular permanent canines were also missing bilaterally but the patient denied having undergone any kind of surgical procedure for removal of canines (Figure 1). To find out the reason for absence of the canines an orthopantomograph was advised. The OPG revealed congenitally missing 33 and 43 (Figure 2). 


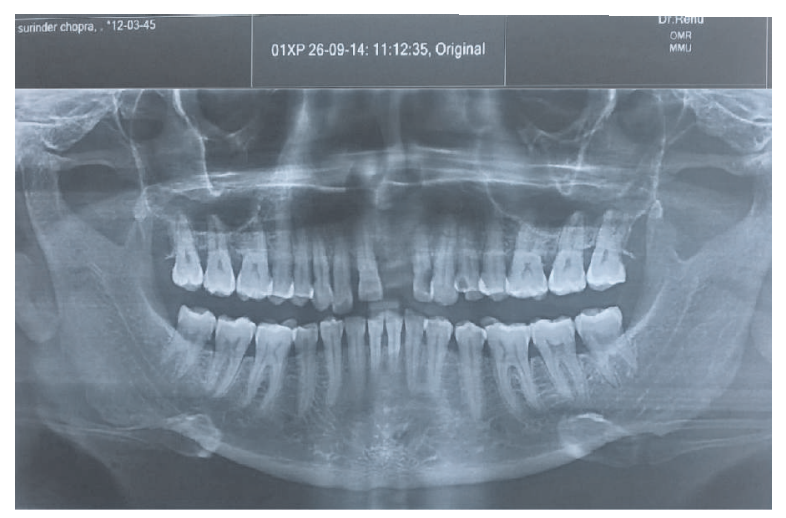

Figure 1: Intraoral photograph showing missing mandibular canines.

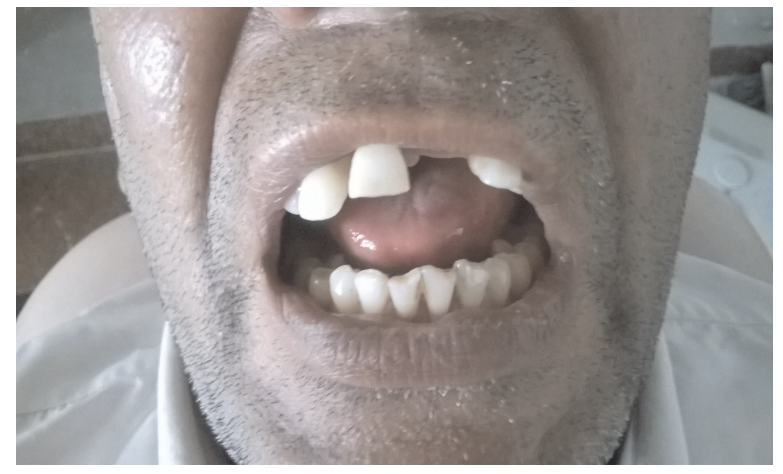

Figure 2: Orthopantomograph showing agenesis of mandibular canines bilaterally

\section{DISCUSSION}

Hypodontia of primary teeth appears to be inherited in an autosomal dominant fashion, with incomplete penetrance and variable expressivity, whereas some cases present an autosomal recessive or sex-linked pattern. ${ }^{4}$ The likelihood ratio of eruption of permanent canines even though their primary predecessors are not erupted was found zero. ${ }^{5}$ Congenital absence of the canines in the permanent dentition is very rare with the incidence reported to be $0.23 \%$ by Bergestrom ${ }^{6}, 0.45 \%$ by Davis $^{7}, 0.18 \%$ by Fukuta. ${ }^{8}$ Studies have shown that hypodontia affects the maxillary arch more than the mandibular arch. The incidence of congenitally missing permanent canine was found to be $0.1 \%$ in the maxilla and $0.02 \%$ in mandible, Muller et al reported only three incidences of missing mandibular canines in 14940 North American children, whereas 15 missing maxillary canines were found. ${ }^{9}$ Davis ${ }^{7}$ found no cases of missing mandibular canine in 1093 students, however five cases of missing maxillary canine were seen.

Hypodontia may also be a consequence of absence or severe damage to the appropriate dental lamina. The dental lamina is extremely sensitive to external insults like trauma, infection, radiation, physical obstruction or endocrine disturbances. ${ }^{10}$ Disruption of the dental lamina, space limitation, functional abnormalities of the dental epithelium or failure of initiation of the underlying mesenchyme - are all possible histologic explanations for that phenomenon. ${ }^{11}$ Studies have shown that local, endocrine, genetic and environmental factors are responsible for hypodontia. Msxl (Muscle Segment $B o x$ ) is believed to play an important role in tooth development. Familial tooth agenesis is transmitted as an autosomal dominant, recessive or X-linked condition. ${ }^{12}$ List of the genes and molecular pathways involved in tooth agenesis include ${ }^{12}$

$\begin{array}{ll}\checkmark & \text { Wnt/b-catenin/LEF1 } \\ \checkmark & \text { MsxI } \\ \checkmark & \text { Msx2 } \\ \checkmark & \text { SHH } \\ \checkmark & \text { P63 } \\ \checkmark & \text { Pitx2 } \\ \checkmark & \text { Runx2/Cbfa1 }\end{array}$

The explanation for a very rare phenomenon, like in the presented case, can be genetic, environmental, or more likely the combination of both. Loss of developing tooth buds, as discussed earlier, appears to be genetically controlled. In spite of this, the environment may also influence the final result. Geographic location and fluoridation status at time of amelogenesis were not found to be related to the prevalence of hypoplasia in canines. ${ }^{13}$

Various treatment options for missing mandibular canine include no treatment, closure of spaces orthodontically, restoration with removable or fixed partial dentures and restoration with implantsupported prosthesis. ${ }^{13}$ In our case since there was no space present in the dentition and the patient was asymptomatic, no treatment was done. 


\section{CONCLUSION}

Understanding of a rare condition like congenitally missing bilateral permanent mandibular canines may be enhanced by reporting of such cases. Early diagnosis and management is desired to improve the oral health of the patient.

\section{REFERENCES}

1. Endo T, Ozoe R, Kubota M, Akiyama M, Shimooka S. A survey of hypodontia in Japanese orthodontic patients. Am J Orthod Dentofacial Orthop. 2006; 129(1): 29-35.

2. Bäckman B, Wahlin YB. Variations in number and morphology of permanent teeth in 7- year-old Swedish children. Int J Paediatr Dent. 2001; 11(1): 11-7.

3. Rose JS. A survey of congenitally missing teeth, excluding third molar in 6000 orthodontic patients. Dent Rec. 1966; 17: 107-14.

4. Marinelli A, Giuntini V, Franchi L, Tollaro I, Baccetti T, et al. Dental anomalies in the primary dentition and their repetition in the permanent dentition: a diagnostic performance study. Odontology 2012; 100: 22-7.

5. Brook AH. Multilevel complex interactions between genetic, epigenetic and enviromental factors in the aetiology of anomalies of dental develolpment. Arch Oral Biol 2009; 54: s3-17.
6. Bergostrom K. An orthopantomographic study of hypodontia, supernumeraries and other anomalies in school children between the ages of 8-9 years. An epidemiological study. Swed Dent J 1977; 1: 145-57.

7. Davis PJ. Hypodontia and hyperdontia of permanent teeth in Hongkong's school children.Community Dent Oral Epidemiol. 1987; 15:218-20.

8. Fukuta Y, Totsuka M, Takeda Y, Yamamoto H. Congenital absence of permanent canine: a clinico-statistically study. J Oral Sci. 2004; 46(4): 247-52.

9. Muller TP, Hill IN, Peterson AC, Blayney JR. A survey of congenitally missing permanent teeth. J Am Dent Assoc. 1970; 81:101-7.

10. Neville BW, Damm DD, Allen CM, Bouquot JE (2009) Oral and Maxillofacial Pathology. (3rdedn), Saunders.

11. Stewart RE, Barber TK, Troutman KC, Wei SHY (1982) Pediatric dentistry, scientific foundations and clinical practice. Mosby co, St Louis.

12. Kohli A, Gupta K, Singh G, Sharma K Congenitally Missing Bilateral Permanent Mandibular Canines. Rama Univ J Dent Sci. 2015;2(2): 29-30.

13. Birnboim-Blau G, Spierer S, Keinan D. Congenital Bilateral Missing Primary Mandibular Canines while their Successors Exist: A Case Report. Dentistry 2014; 4: 224. 